\title{
A religiosidade na poesia de Bárbara Heliodora, a heroína da Inconfidência Mineira
}

Carla Pereira de Castro ${ }^{1}$

http://orcid.org/0000-0002-8593-0172

http://lattes.cnpq.br/9952304114865676

Enviado em: 30/07/2018

Aceito em: 11/03/2019

RESUMO: Bárbara Heliodora Guilhermina da Silveira nasceu em 1758 ou 1759, não se sabe exatamente o dia, em São João Del-Rei, MG. Foi esposa de Alvarenga Peixoto, advogado, poeta e inconfidente, com quem partilhou a vida e boa parte do destino. Inicialmente viveram juntos e só se casaram em 1781. Desta união nasceram quatro filhos. Os historiadores da época contam que Bárbara Heliodora exercia grande influência sobre seu marido e participava ativamente das ideias e planos da Inconfidência Mineira. Faleceu em 24 de maio de 1819, em São Gonçalo do Sapucai, aos 60 anos. Deixou publicado a obra Conselhos aos mens filhos. A poetisa também é atribuída a escrita de um soneto oferecido a filha Maria Ifigênia. No estudo desenvolvido serão analisados os aspectos relacionados a religiosidade presente nesses dois textos da escritora.

PALAVRAS-CHAVE: Poesia, Bárbara Heliodora, Inconfidência, Mulher, Religiosidade

ABSTRACT: Bárbara Heliodora Guilhermina da Silveira was born in 1758 or 1759, it is not known exactly the day, in São João Del-Rei, MG. She was the wife of Alvarenga Peixoto, lawyer, poet and inconfident, with whom she shared life and a good part of destiny. Initially they lived together and only married in 1781. From this marriage four children were born. The historians of the time tell that Barbara Heliodora exerted great influence on her husband and participated actively in the ideas and plans of the Inconfidência Mineira. He died on May 24, 1819, in São Gonçalo do Sapucai, at the age of 60 . He published the book Counsels to my children. The poetess is also attributed the writing of a sonnet offered to daughter Maria Iphigenia. In the study developed will be analyzed the aspects related to the religiosity present in these two texts of the writer.

KEY WORDS: Poetry, Bárbara Heliodora, Inconfidence, Woman, Religiosity

De heroína a musa da Inconfidência, é assim como Bárbara Heliodora é reconhecida, na história das revoluções e da literatura feminina. Poucos são os registros em que encontramos relatos de sua vida ou de sua escrita nos livros que se dedicam aos estudos literários. Em decorrência dessa ausência nos propomos a analisar os textos que foram encontrados, diferentemente dos recortes já realizados nos detivemos, as marcas de religiosidade encontrada em seus escritos.

Bárbara Heliodora Guilhermina da Silveira teria nascido entre 1758 e 1759. Seus historiadores não confirmam a precisão dessa data por falta de fontes documentais. Segundo os estudos de Nelly Coelho em seu Dicionário Critico de Escritoras Brasileiras, seu pai foi um dos primeiros advogados formados na época, profissão essa muito ilustre e respeitada para a

\footnotetext{
${ }^{1}$ Mestranda em Letras, área de concentração Literatura Comparada na UFC e professora da rede Estadual de Ensino do Ceará. É autora da obra A Vida em Versos e participa de diversas antologias locais e nacionais. E-mail: professoracarlacastro@gmail.com
}

https://periodicos.unifap.br/index.php/letras Macapá, v. 8, n. 3, $2^{\circ}$ sem., 2018 
sociedade.

Era filha do Dr. José da Silva e Sousa, natural de Tomar (Portugal), um dos primeiros advogados formados que se estabeleceram na capitania de Minas Gerais e a quem se devem as gestões para a construção da famosa igreja de São Francisco de Assis em São João del Rey, onde sempre residiu. Entre seus ancestrais, está o bandeirante Amador Bueno da Veiga, comandante paulista na Guerra dos Emboabas, que aconteceu na região, onde mais tarde se instalou a Vila de São João del Rey, em 08.12.1713. (Coelho, 2002, p. 85).

O empenho na gestão para a construção da igreja revela a religiosidade presente na família.

Bárbara Heliodora nasceu na cidade de São João del Rei, na Rua da Prata, seus pais eram o Dr. José da Silveira e Sousa e D. Maria Josefa Bueno da Cunha. Teve como companheiro e esposo o inconfidente Alvarenga Peixoto. Na época a colônia vivia momentos de tensão em relação as cobranças de impostos que eram exigidos da população. Sobre essa fase da história e o relacionamento entre Bárbara e Alvarenga, encontramos uma breve descrição na obra de Joaquim Norberto de Sousa e Silva, Brasileiras Célebres.

A rica capitania de Minas Gerais achava-se sob a pressão do terror e das perseguições. Ah! que calamidade! Dir-se-ia que o anjo da agonia tinha estendido as asas enlutadas sobre Vila Rica, e que o hino da consternação ecoava de todos os lábios. Por toda a parte a justiça seqüestrava. Não exigia tão-somente o ouro, as jóias, os trastes, os escravos e os animais domésticos; sequestrava também a roupa do corpo, roubava também o teto, o lar e o pão, e a família isolada, malquista, aí ficava nua à face do céu, aí vivia sem habitação, aí morria sem alimento! O medo precedia os infelizes atirados como náufragos da tempestade política a praias inóspitas. Eram os lázaros da inconfidência, cujo contato se temia como se tisnasse a mais pura e cândida reputação. Ante eles se fechavam todas as portas, porque a piedade e a compaixão eram símbolos de cumplicidade no dicionário do governo colonial. Ainda a sentença não havia impresso o ferrete da infâmia sobre os descendentes dos mártires da independência brasileira e já sobre eles pesava a mão negra e mirrada do destino acerbo que os aguardava! Descendente das mais notáveis família da capitania de São Paulo, distinguia-se também dona Bárbara Heliodora Guilhermina da Silveira pela sua formosura e pelas suas prendas, e esses dotes, que lhe deram a natureza e a educação, atraíram a atenção, mereceram a simpatia, cativaram o amor do coronel Inácio José de Alvarenga Peixoto. Era ele poeta como Tomás Antônio Gonzaga e como o cantor da beleza de Vila Rica, celebrou a beleza da vila de São João d'Rei. Dotada de imaginação brilhante, sentindo o estro borbulhar-lhe no cérebro, a jovem donzela retribuía por afeição e folgava com poder pagar-lhe igualmente versos por versos, e o comércio das musas santificou e engrandeceu aquele amor em que mutuamente se abrasaram. Bacharel formado em cânones na universidade de Coimbra e despachado ouvidor da comarca do Rio das Mortes, depois de ter servido de juiz de fora de Cintra em Portugal, Inácio José de Alvarenga, abandonou a carreira que abraçara com tantos sacrifícios, que tão longas viagens, e tão aturados estudos lhe havia custado; esqueceu-se para sempre do seu ninho natal, esse majestoso Rio de Janeiro com seu céu esplêndido, com sua magnífica baía, suas soberbas montanhas, suas belas florestas, e estabeleceu-se no país cofre dos diamantes e de gemas de ouro. (pág. 131-132)

Alvarenga Peixoto e Bárbara Heliodora viveram juntos por algum tempo, e só depois contraíram matrimônio, como relata Vasconcellos na obra Escritoras Brasileiras do Século XIX, organizada por Muzart.

Alvarenga Peixoto e Bárbara Heliodora viveram juntos por algum tempo, só se casaram, por portaria do bispo de Mariana, de 22 de dezembro de 1781, quando Maria Ifigênia, filha do casal, já contava três anos de idade.

https://periodicos.unifap.br/index.php/letras

Macapá, v. 8, n. 3, $2^{\circ}$ sem., 2018 
Bárbara Heliodora, não teve uma vida fácil, perdeu sua filha Maria Ifigênia aos 13 anos, consequência de uma queda de cavalo, e depois da prisão e degredo de seu marido teve que assumir os bens e negócios da família, o que fez com bastante competência. Ao final da vida foi tida como demente, mas esse fato é contestado por boa parte dos historiadores.

A comentada demência de Bárbara Heliodora a teria alcançado já ao final da vida, negando-lhe a compreensão de seus atos, mas nem todos os historiadores aceitam tal história. Alguns citam que a razão de tal "demência" teria sido a venda para um de seus filhos de propriedades com o objetivo de fugir à execução judicial que pesava sobre eles. A única forma da Coroa Portuguesa anular tal ato, já que se sentia prejudicada, seria declarála "em estado de demência".

Bárbara Heliodora morreu em 24 de maio de 1819, na cidade mineira de São Gonçalo do Sapucaí. Conforme sua certidão de óbito a causa da morte foi Tísica (Tuberculose), e foi sepultada na Igreja Matriz da cidade.

A "Heroína da Inconfidência" é até hoje lembrada pelo seu espírito libertário, que encontrou perfeita acolhida na Conjuração Mineira. Fruto de uma época difícil e incerta, Bárbara e Alvarenga avançaram por caminhos difíceis e perigosos. A produção literária da ambos não foi extensa, mas foi bela. Amor, carinho e fidelidade estão sempre presentes em suas palavras, e certamente espelham o que sentiram em suas vidas.

Dela se conhecem doze sextilhas, estrofes com seis versos, intituladas Conselhos a meus filhos, publicadas nas Obras poéticas de Inácio de Alvarenga Peixoto, em 1865.

Conselhos aos meus filhos.

Meninos, eu vou ditar

As regras do bem viver,

Não basta somente ler,

É preciso ponderar,

Que a lição não faz saber,

Quem faz sábios é o pensar.

Neste tormentoso mar

D'ondas de contradições,

Ninguém soletre feições,

Que sempre há de enganar;

Das caras a corações

Há muitas léguas que andar.

Aplicai ao conversar

Todos os cincos sentidos,

Que as paredes têm ouvidos

E também podem falar:

Há bichinhos escondidos,

Que só vivem de estudar.

Quer quer males evitar

Evite-lhe a ocasião

Que os males por si virão,

$\mathrm{E}$ antes que ronque o trovão,

Manda a prudência ferrar.

Não vos deixei enganar

https://periodicos.unifap.br/index.php/letras

Macapá, v. 8, n. 3, $2^{\circ}$ sem., 2018 
Por amigos, nem amigas,

Rapazes e raparigas

Não sabem mais que asnear;

As conversas e as intrigas

Servem de precipitar.

Sempre que vos deveis guiar

Pelos antigos conselhos,

Quem dizem que os ratos velhos

Não há modo de os caçar;

Não batam ferros vermelhos,

Deixem um pouco esfriar.

Se é tempo de professar

De taful o quarto voto,

Procura capote rôto,

Pé de banco de bilhar,

Que seja sábio pilôto

Nas regras de calcular.

Se nos mandarem chamar,

Para ver uma função,

Respondei sempre que não,

Que tendes em se cuidar:

Assim se entende o rifão:

Quem está bem deixa-se estar.

Deveis-vos acautelar

Em jogos de paro e topo

Prontos em passar o copo

nas angolinhas do azar:

Tais as fábulas de Esopo,

Que vós deveis estudar.

Quem fala, escreve no ar,

Sem por vírgulas nem ponto,

E pode quem conta os contos,

Mel pontos acrescentar;

Fica um rebanho de tontos

Sem nenhum adivinhar.

Com Deus e o rei não brincar,

É servir e obedecer,

Amar por muito temes,

Mas temer por muito amar,

Santo temor de ofender

A quem se deve adorar!

Até aqui pode bastar,

Mas havia que dizer,

Mas eu tenho que fazer,

Não me posso demorar,

$\mathrm{E}$ quem sabe discorrer

Pode o resto adivinhar. 
Observamos nessa sextilha o amor maternal de Bárbara Heliodora nos cuidados aos filhos e nas orientações que eles deviam seguir para ter um bom caminho. Bárbara Heliodora e Alvarenga Peixoto tiveram quatro filhos, Maria Ifigênia, José Eleutério, João Damasceno (trocou o nome para João Evangelista Alvarenga) e Tristão Antônio.

Logo na estrofe inicial que traz orientações sobre os conselhos, a autora adverte que não será apenas o conhecimento, o saber que irão faze-los ter discernimento, mas o mais importante é o saber pensar. Refletir sobre os seus atos e avaliar que melhor decisão a ser tomada em cada situação.

A quantidade de sextilhas, doze poderia estar relacionada aos meses do ano, ou ao número de apóstolos que seguiram Jesus. Encontramos ainda na religião outras simbologias relacionadas a esse numeral. Hércules teve 12 trabalhos, a távola redonda do mito arturiano tinha 12 cavaleiros, a coroa do Rei da Inglaterra é incrustrada de 12 pedras, entre muitos outros exemplos. O fato é que o número 12 possui fortes significados simbólicos na história, religião, astrologia e magia.

$\mathrm{Na}$ segunda estrofe, encontramos a referência ao provérbio "Quem vê cara não vê coração". Das caras a corações, no quinto verso. Advertindo sobre a facilidade de nos enganarmos quando apenas apreciamos a beleza externa mas não conhecemos o conteúdo interior.

$\mathrm{Na}$ quarta estrofe o caminho indicado para que se evitem os malesé a prudência quanto a ocasião.Nas estrofes que se seguem, a poetisa sugere que não acredite em falsos amigos, ter cuidado com as companhias e está sempre com a mente ocupada para evitar intrigas.

$\mathrm{Na}$ décima primeira estrofe a referência a Deus e ao rei nos faz evidenciar a submissão, o respeito e a reverência a igreja e a nobreza pelo povo, e em especial por Bárbara Heliodora e sua família, por temer reações e castigos a eles infringidos. A adoração deve ser exercida tanto a Deus quanto ao rei numa clara demonstração de imposição.

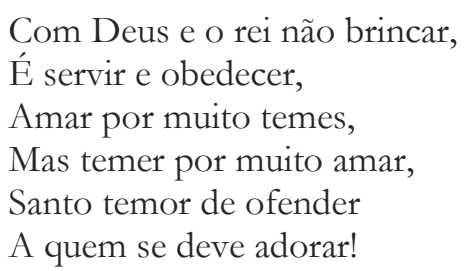

Através de suas palavras podemos destacar a utilização de seus textos para apresentar não apenas aos filhos, mas a todos aqueles que tivessem contato com os seus escritos, orientações para a vida e desfrutando-a com harmonia.

Bárbara Heliodora é reconhecida como uma das primeiras escritoras brasileiras, mulher que enfrentou com coragem o exílio do amado, teve voz e exerceu grande influência nas revoltas da Inconfidência. Em uma época em que a mulher tinha poucos caminhos, dentre eles: o casamento ou a prostituição. Como podemos evidenciar no estudo A Mulher na História do Brasil, por Mary Del Priore.

Em virtude das enormes distâncias entre discursos e as práticas sobre o uso dos corpos, e estando articuladas com a sexualidade não domesticada e com a luta das autoridades civis e eclesiásticas para transformar o "tálamo conjugal”, na única forma de sexo ilícito, as prostitutas do Brasil colonial foram úteis para a construção e valorização do seu oposto: a mulher pura, identificada como a Virgem Maria e distante da sexualidade transgressora. Pacificadoras da violência sexual contra as donzelas casadouras e do desejo que pusesse em risco a fidelidade às 
esposas, as prostitutas, aos olhos da Igreja, eram a salvaguarda do casamento moderno. (PRIORE, 1989, pág. 22)

Na obra de 1875, A Igreja e O Estado o Cathólico e o Cidadão, de Joaquim Pinto de Campos, temos acesso as orientações impostas pela igreja em relação a mulher e a importância de seu papel na família. O autor critica ainda a educação oferecida à mulher e questiona como ela irá exercer o seu papel sem ter o conhecimento. E reclama ainda por aquelas que não têm recursos, ficaram praticamente a mercê da sorte.

Os nossos collegios de meninos geralmente ensinam muito francez,muita philosophia, mas, que eu saiba, pouco explicam o PadreNos"o.Ainda mais grave é o ensino em collegios de meninas. Amulherpóde e deve ser o grande instrumenlo da regeneração;mas para isso cumpre oubstituir sua posição actual de idolodoura oou machinareproduclora. Orna nação é um aggregado de familias; lar domestico é a mulher. Como ba de educar seus filhos,instruil-os. torna-los tementes a Deus, uteis à patría; como ha deusar de seu immenso poder sobre o marido. se a sua intelligeneiaincu; (a lhe não proporcionar os meios de aproveitar tão vasta, tãolegitima 'nnuencia ? A nossa educação feminina é hoje quasiexcluosivamente a dos bailes. das salas, das ostentações e das miserias.e as que vivem fóra das cidades, ou que não I:0ssuem fortuna, vegetam na ignorancia, por se entender que a mulher, de per si,é nada! (CAMPOS, 1875, página 12).

Além das sextilhas Conselhos aos meus filhos é atribuída a Bárbara Heliodora um soneto a quem dedica a sua querida filha que faleceu precocemente. No texto de Vasconcellos, na obra Escritoras Brasileiras do Século XIX encontramos uma descrição das habilidades de Maria Ifigênia.

Os estudiosos de Bárbara Heliodora fazem sempre menção à beleza de sua filha Maria Ifigênia. Segundo Joaquim Norberto "tão formosa aos doze anos que lhe deram o nome de princesa do Brasil e essa antonomásia tornou-se popular". Ao contrário das outras meninas de seu tempo recebeu de seus pais uma educação primorosa: "a formosa menina estudava e se aperfeiçoava não só na sua língua como nas estrangeiras e ainda nas belas-artes; a dança, a música, o desenho ilustravam-lhe o espírito e lhe serviam de agradável entretenimento. (ZAHIDE, 1999, Página 61).

\section{SONETO}

Amada filha, é já chegado o dia, em que a luz da razão, qual tocha acesa, vem conduzir a simples natureza:

-é hoje que o teu mundo principia.

A mão, que te gerou, teus passos guia; despreza ofertas de uma vá beleza, e sacrifica as honras e a riqueza às santas leis do Filho de Maria.

Estampa na tua alma a Caridade, que amar a Deus, amar aos semelhantes, são eternos preceitos da Verdade.

Tudo o mais são idéias delirantes; procura ser feliz na Eternidade, que o mundo são brevíssimos instantes. 
Podemos constatar o âmbito familiar em que o poema foi escrito. A religiosidade se apresenta em todas as estrofes. Na primeira a referência ao início de um mundo novo, na seguinte a obediência as leis divinas. Na terceira estrofe a palavra "caridade" nos remete ao dever moral de ajudar ao próximo de amar não somente

a Deus, mas também ao tteu irmão, ao teu semelhante que são os mandamentos primordiais da Lei de Deus. Amar a Deus sobre todas a coisas e ao teu próximo como a ti mesmo. Encontramos essa passagem na bíblia, no engelho de Mateus, Capítulo 22, versículos 34 ao 40.

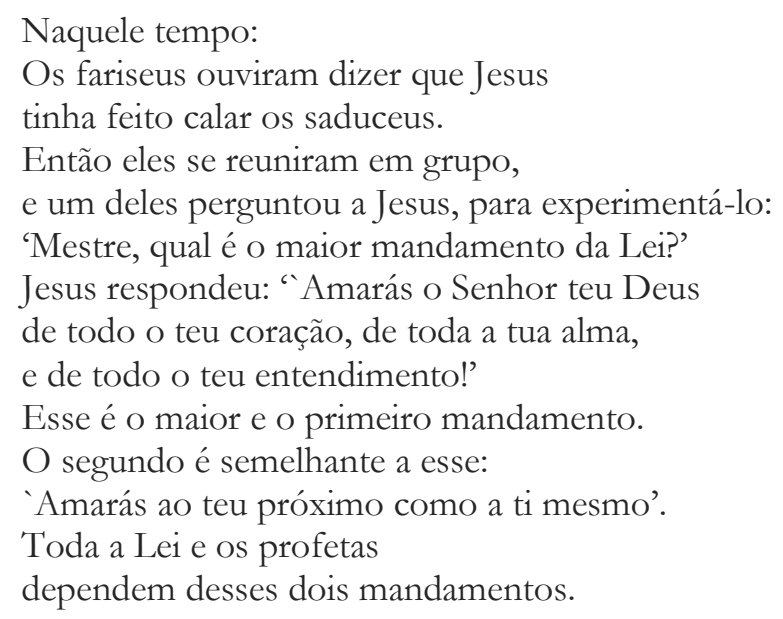

Por meio dessa análise podemos constatar marcas expressas de religiosidade, e do contexto afetivo familiar nos textos da poetisa Bárbara Heliodora. A submissão ao rei e a Deus são evidentes pois o medo da delação e das perseguições eram constantes na época.

Os estudos não se esgotam na produção desse texto. As lacunas na história das escritoras brasileiras anseiam ser recuperados. Apesar do avanço em relação ao resgate das escritoras do período colonial, temos ainda grandes desafios a serem enfrentados. A falta de informação e de registros documentais é o maior deles mas com esforço e dedicação levaremos a tona a história dessas escritoras, guerreiras, revolucionárias, mulheres que enfrentaram uma pátria na conquista dos seus direitos e de sua fala.

\section{Referências}

COELHO, Nelly Novaes. Dicionário Crítico de Escritoras Brasileiras. São Paulo: Escrituras Editora, 2002.

DEL PRIORE, Mary (Org.). História das mulheres no Brasil. 10. ed. São Paulo: Contexto, 2012. 678 p.

HOORNAERT, Eduardo. A igreja no Brasil-colônia (1550-1800). São Paulo: Brasiliense, 1982. 92p. (Tudo é historia ; 45) ISBN (broch.).

MOISÉS, Massaud. A análise literária/ Massaud Moisés. SãoPaulo :Cultrix, 2007.16'reimpr. da. l'. ed. de1969.

MUZART, ZahidéLupinacci. Escritoras brasileiras do século XIX: antologia. $1^{\mathrm{a}}$. Ed. Ver. - Florianópolis: Editora Mulheres; Santa Cruz do Sul: EDUNISC, 1999.

PEREIRA, Cláudia Gomes. Contestado Fruto: a poesia esquecida de Beatriz Brandão (1779- 1868). Lisboa: CLEPUL, 2011, 358 p. 
PRIORE, Mary Del. Religião e religiosidade no Brasil Colonial. São Paulo: Ática, 2002.

PRIORE, Mary Del. A Mulher na História do Brasil. 2ª Edição. São Paulo: Contexto, 1989.

http://www2.senado.leg.br/bdsf/handle/id/174425 (Acesso em 25/06/2018).

http://www2.senado.leg.br/bdsf/handle/id/224206(Acesso em 25/06/2018).

http://www.paroquiadivino.org.br/index.php/amar-a-deus-sobre-todas-as-coisas-e-ao-proximomt-2234-40/(Acesso em 25/06/2018). 